\title{
DIALÉTICA DO PROCESSO DE TRABALHO DA LIGA DE HIPERTENSÃO ARTERIAL ***
}

\author{
Marcia Regina Car* \\ Emiko Yoshikawa Egry**
}

\begin{abstract}
CAR,M.R.;EGRY,E.Y. Dialética do processo de trabalho da Liga de Hipertensão Arterial Rev.Esc.Enf.USP, v. 30, n.2, p. 297-309, ago. 1996.

Buscou-se compreender o fenômeno da assistência à saúde desenvolvida na Liga de Diagnóstico e Tratamento da Hipertensão Arterial do Hospital das Clínicas da Faculdade de Medicina da USP, evidenciando suas contradições através da articulação dos elementos constitutivos deste processo de trabalho,contidos nos depoimentos de seus agentes.As concepçöes dos agentes sobre este processo de trabalho expressaram uma práxis reiterativa, consagrando e consolidando um dado saber específico que,para além de ser Meio da ação interventiva sobre o Objeto,configurase num saber ideológico dominante na área de saúde.
\end{abstract}

UNITERMOS: Processo de Trabalho. Hipertensão Arterial.

\section{INTRODUÇÃO}

A preocupação com a hipertensão arterial, dita essencial, intensificou-se a partir da década de 50, como um problema da área de saúde. Isto aconteceu principalmente devido à sua freqüente associação com o risco de mortalidade por doenças cárdio-vasculares.

Essa preocupação com a hipertensão arterial vem sendo, portanto, justificada fundamentalmente pelos índices de mortalidade cárdio-vascular, que cresceram com a industrialização, tanto nos países desenvolvidos, como nos subdesenvolvidos (LAURENTI; 1985).

\footnotetext{
* Enfermeira. Doutora em Enfermagem. Professor Doutor do Departamento de Enfermagem Médico-Cirúrgica da Escola de Enfermagem da USP.

** Enfermeira. Doutora em Saúde Pública. Professora Associada do Departamento de Enfermagem em Saúde Coletiva da Escola de Enfermagem da USP.

*** Parte da Tese: CAR, M.R. Da aparência à essência: a práxis assistencial dos trabalhadores da Liga de Hipertensa o Arterial. São Paulo, 1993. 125p. Tese(Doutorado)-Escola de Enfermagem, Universidade de São Paulo.
} 
A relevância do problema da hipertensão nos países ocidentais, passou a envolver, após a metade deste século, a atuação de organismos internacionais como a Organização Mundial da Saúde (OMS). Este organismo juntamente com o Fundo Monetário Internacional foram criados no pós-guerra, "(...) para levar adiante os propósitos de criação de uma nova ordem internacional na área dos problemas econômicos e sociais(...)" (INFANTE; ALVAREZ; 1991). Assim, já no final da década de 50, a OMS apresentou o primeiro informe técnico de peritos em doenças cárdio-vasculares e hipertensão, normatizando a classificação e os critérios para os estudos epidemiológicos da hipertensão e da cardiopatia coronariana (ORGANIZACIÓN MUNDIAL DE LA SALUD; 1958).

Os autores norte-americanos, SEMPLE; LINDOP (1992) referem que, ap6s a divulgação desse informe técnico, as companhias de seguro de vida, precocemente, manifestaram-se a respeito da diminuição da expectativa de vida associada à presença da hipertensão arterial. (CHIAVERINI et al. 1985).

Foi também na década de 50 sobretudo nos países ocidentais, que cresceu a industrialização pós-guerra e, com ela, a indústria farmacêutica. Esta investiu, desde então, no desenvolvimento de vários medicamentos, entre eles, os antihipertensivos (HUTCHINS; 1981). Para LUNDE (1989), os anos 50 e 60 foram cenário de uma "explosão farmacológica" devido ao desenvolvimento das ciências biológicas e ao crescente potencial tecnológico e econômico, após a segunda guerra mundial, em especial, nos países ocidentais. $O$ autor comenta que esse potencial econômico e tecnológico possibilitou a aplicação dos conhecimentos resultantes nos marcos de um sistema comercial, onde se dá grande importância aos mecanismos de mercado.

Esta tendência tem revelado a relação íntima que se estabeleceu entre a preocupação com a hipertensão arterial e o seu tratamento com medicamentos anti-hipertensivos. O enfoque na terapêutica medicamentosa articula-se à concepção biológica da doença e seu correspondente modelo clínico de intervenção dominante neste século.Uma causalidade orgânica que elucidasse a hipertensão arterial foi objeto dos estudos de fisiopatogenia. principalmente até o final da década de 40.

Na década de 60, consolidou-se a teoria da multicausalidade da doença, contrapondo-se à unicausal que havia perdido gradativamente a capacidade de responder às necessidades do sistema de atenção a saúde, apoiado numa custosa infra-es trutura técnica de diagnóstico e tratamento. Esse fenômeno evidenciouse principalmente nos países subdesenvolvidos onde a crise do capitalismo obrigou e obriga a uma constante redução dos gastos estatais com a educação e a saúde, entre outros (BREILH; GRANDA: 1986).

"Além disso, a conscientização e o crescimento concomitante da luta popular. especialmente daqueles imensos setores 'marginalizados', contribuiu para que o sistema tivesse que desenvolver um novo marco de interpretação do processo saúde-doença que tornasse factível conduzir ações conseqüentes com 
essas necessidades: descobrir fatores causais na produção do problema fáceis de atacar, com medidas baratas e que permitissem implementar medidas coletivas de controle. Não se tratava de chegar às verdadeiras causas do problema, mas colocar uma cortina ideologica que distorcesse a realidade, e que permitisse ao mesmo tempo, obter resultados pragmáticos adequados" (BREILH; GRANDA; 1986).

Dessa forma, uma vez que à hipertensão arterial,não se pudesse imputar uma causalidade orgânica, os pesquisadores das últimas décadas valeram-se do referencial teórico da multicausalidade (ou dos chamados fatores de risco) na tentativa de explicar a gênese da hipertensão.

Tomando como base a concepção de multicausalidade da doença, a OMS estabeleceu seus programas oficiais $(1978 ; 1982 ; 1983 ; 1986)$, no sentido de orientar as intervenções de saúde junto aos indivíduos e à comunidade, para a prevenção e controle dos agravos cárdio-vasculares.

No Brasil, o Ministério da Saúde apresentou em 1983 o documento intitulado "Guia para Controle da Hipertensão Arterial" (BRASIL; 1983), a fim de subsidiar as ações assistências junto ao indivíduo hipertenso, em todos os serviços de saúde. Tanto esse Documento, quanto o das "Normas Técnicas para o Programa de Educação e Controle da Hipertensão Arterial” (BRASIL; 1988a), mostram evidências de estarem assentados no referencial teórico da concepção multicausal da doença.

A adoção de intervenções de saúde orientadas para os "fatores de risco" tem sido justificada, no Brasil, pelos dados que evidenciam a prevalência da hipertensão arterial - cerca de 10 a $20 \%$ da população adulta -; pelos gastos do Estado com internações hospitalares e com pensões previdenciárias por invalidez temporária ou permanente e, ainda, pelos dados que evidenciaram o aumento do índice de mortalidade noperíodo de 1940 a 1980 por doenças cárdio-vasculares (BRASIL; 1988b).

Porém, o próprio Ministério da Saúde (BRASIL; 1988a; 1988b) admite que "apesar dos avanços científicos e tecnológicos das últimas décadas, que resultam na incorporação de novos recursos de diagnóstico e tratamento, não houve no Brasil, nos últimos 40 anos, qualquer modificação nos coeficientes de mortalidade por doenças cárdio-vasculares e câncer, ao contrário do que ocorreu nos Estados Unidos e em alguns países da Europa. Em 1930, as doenças cárdiovasculares eram responsáveis por apenas $11.8 \%$ das mortes nas capitais brasileiras. Cinqüenta anos depois, em 1980, elas já representavam $30,8 \%$ de todos os óbitos, ou seja, a maior causa mortis entre todas as idades".

A adoção da teoria multicausal da doença foi explicitada no "Consenso Brasileiro para o Tratamento da Hipertensão Arterial" que reuniu em 1990, 56 médicos especialistas nesta área (CONSENSO;1991)..

A preocupação revelada no CONSENSO (1991), "(...) de quem é ou não hipertenso. de quem deve ser tratado com drogas, até quando deve ser buscada 
a redução da pressão arterial e com que droga (ou drogas)", destaca a abordagem da assistência ao doente com hipertensão arterial, prioritariamente, através da terapêutica medicamentosa. Sugeriria isto a existência de uma contradição teórico-prática onde, no nível do discurso seria colocada a teoria multicausal, e no seu desdobramento no nível das ações e procedimentos se destacaria a intervenção para uma causa única?

Os serviços de saúde têm sido estruturados no Brasil, de modo geral, de acordo com o paradigma médico-biológico da doença. Assim, o atendimento daqueles doentes com hipertensão arterial que têm acesso aos serviços públicos de saúde é realizado consoante o modelo clínico individual, de maneira geral, hipervalorizando a ação do profissional médico. Nesses serviços a enfermagem desenvolve atividades tais como a pré e a pós consulta médica e outras ações ditas educativas, no sentido de orientar o doente para o tratamento médico estabelecido, configurando o atrelamento de suas ações ao mesmo paradigma.

As discussões sobre as limitações decorrentes do paradigma biologico da doença e do modelo clínico que lhe 6 correspondente, intensificaram-se na América Latina a partir do final dos anos 60, época em que foi sendo reconhecida a importância do conhecimento das ciências sociais enquanto instrumental teóricoconceitual e metodologico para as reflexões sobre a prática, no campo da saúde.

O entendimento de que o processo saúde-doença tem vínculos estreitos com a organização social não é recente. Embora ele já existisse no século passado, foi desprezado pelo enfoque biologico que prometia ter, e efetivamente teve, avanços rápidos na medicina.

O ressurgimento dessa polêmica, nos anos 60 , encontra suas razões tanto no desenvolvimento interno da medicina, como na sociedade com a qual ela se articula (LAURELL; 1983). O auge dessa polêmica encontra explicação na crescente crise política e econômica, que gera uma nova etapa de lutas sociais particulares, em diferentes países. Por outro lado, o principal motivo interno à medicina que dá origem ao questionamento do paradigma médico-biológico é encontrado na dificuldade de gerar conhecimentos que permitissem a compreensão dos problemas de saúde da coletividade, tais como, as doenças cárdio-vasculares e o câncer (LAURELL: 1983).

Surgiu assim um movimento contra-hegemônico que vem gerando. principalmente na América Latina, novos conhecimentos na área de saúde. A contra-hegemonia é dada pela sua fundamentação no referencial tebrico-filosófico do materialismo histórico e dialético que se opõe à concepção idealista de mundo. representada pelo positivismo, dominante neste século na produção do saber na área da saúde.

No referencial materialista histórico e dialético, o processo saúde-doença da coletividade é entendido como "o modo específico pelo qual ocorre no grupo o processo biologico de desgaste e reprodução, destacando como momentos particulares a presença de um funcionamento biologico diferente com 
consequência para o desenvolvimento regular das atividades cotidianas, isto é, o surgimento da doença" (LAURELL; 1983).

Se esse referencial teorico-filosófico não é hegemônico, os correspondentes conceitos tais como sociedade, homem e processo saúde-doença também não estão sendo operacionalizados nos sistemas e serviços de saúde. Equivale dizer que predomina hoje, a adoção de modelos teóricos-conceituais mais enraizados na fundamentação do funcionalismo-positivista, apesar da intensificação do processo de reflexão sobre as práticas de saúde.

A concepção marxista do trabalho enquanto processo, vem sendo utilizada como base para compreensão das práticas de saúde. GONÇALVES (1988; 1992) e um dos autores brasileiros, que vem produzindo importantes reflexões sobre as práticas de saúde, fundamentadas na concepção marxista do processo de trabalho.

Este autor, superando a visão idealista das práticas de saúde concebe-as enquanto trabalho. Em que pesem as especificidades concernentes a essas práticas, principalmente por terem como objeto o homem, elas são trabalho porque se inserem sob determinadas estruturas sociais com os especificos modos de produção. Dessa forma. as práticas de saúde apresentam os mesmos elementos constitutivos do processo de trabalho humano em geral - Objeto, Meios e Finalidade.

É essa consonância que levou a pesquisadora a re-olhar a prática da qual é um dos agentes. Essa prática, desenvolvida na Liga de Diagnóstico e Tratamento da Hipertensão Arterial do Hospital das Clínicas da Faculdade de Medicina na Universidade de São Paulo (Liga), não tem se mostrado transformadora da qualidade de saúde dos usuários deste serviço mesmo quando se toma como critério específico de análise o controle da hipertensão arterial Nesse sentido, se faz necessária a revisão das concepções que orientam essa prática compreendendo-a como um trabalho, trabalho este que se desenvolve num micro espaço institucional concreto. articulado ao processo de trabalho em saúde.

Tal como no caso da compreensão do fenômeno saúde-doença do hipertenso que necessita recuperar a visão da epidemiologia social e entender as reais causas do problema da hipertensão arterial inseridas no social mais amplo, a compreensão do trabalho da Liga como prática social implicou na adoção de um ou tro referencial teórico-filosófico. Neste sentido. o materialismo histórico e dialético enquanto referencial de interpretação e análise vai além da aparência fenomênica do objeto. buscando conhecer sua substância * e sua articulação com a estrutura social cada vez mais ampla.

\footnotetext{
"Kosik explica que o marxismo "definiu como "substância" a dinâmica mesma do objeto, a sua dialética. Por conseguinte. conhecer a substância não significa reduzir os "fenômenos" à substância dinamizada. vale dizer a algo que se esconde por detrás dos fenômenos e que deles năo depende; significa conhecer as leis do movimento da coisa em si. A "substância é o próprio movimento da coisa ou a coisa em movimento". KOSIK, K. Dialética do concreto. Rio de Janeiro, Paz e Terra, 1986. p. 27-8.
} 
Para alcançar a finalidade proposta, o presente estudo teve por objetivos:

- evidenciar as contradições existentes na prática de saúde da Liga de Hipertensão Arterial, através da articulação dos elementos constitutivos desse processo de trabalho;

- evidenciar as raízes ideológicas dos saberes que orientam o processo de trabalho na Liga, pela exposição dos elementos constitutivos deste processo contidos na narrativa assistencial de seus agentes;

- interpretar historicamente a dinâmica das transformações da prática assistencial da Liga de Hipertensão Arterial;

- identificar caminhos para a transformação do processo de trabalho na Liga de Hipertensão Arterial.

\section{MÉTODO}

A fundamentação teórico-metodológica deste estudo está baseada nas leis principais e secundárias do materialismo histórico e dialético,além das categorias analíticas dos processos de trabalho e de saúde-doença baseados na mesma concepção marxista.

O material empírico deste estudo foi obtido através de entrevista com dez agentes médicos e de enfermagem, que atuavam na Liga no momento. Deles foi solicitada a descrição de uma situação vivenciada de atendimento na Liga que envolvesse o próprio profissional, o doente e outros agentes do trabalho.

Os depoimentos obtidos dessas entrevistas foram submetidos a uma análise qualitativa fundamentada em FIORIN;SAVIOLI(1991), que permitiu a extração dos temas contidos na narrativa assistencial dos agentes.

Os temas depreendidos desses discursos foram expressos em frases e agrupados através de suas articulações com os elementos constitutivos doprocesso de trabalho,ou seja, Objeto. Finalidade e Meios/Instrumentos.

\section{DIALÉTICA DO PROCESSO DE TRABALHO NA LIGA DE HIPERTENSÃO ARTERIAL}

Pode-se depreender das representações tematizadas nos discursos dos agentes do trabalho na Liga que, na lógica de sua organização interna enquanto processo evidenciam-se poucas contradições. Já não se pode afirmar o mesmo quando se examina a exterioridade. ou seja, suas articulações com totalidades maiores da realidade objetiva, quais sejam. o sistema de saúde, o sistema educacional, as políticas sociais e econômicas. 
Os discursos dos agentes apontam claramente a hegemonia do poder/saber do médico no processo de trabalho desenvolvido na Liga, reiterando relações hierárquicas rígidas, ou seja, de dominação-subordinação, em relação aos agentes não médicos. Alguns temas, expressos em frases extraídos dos depoimentos dos médicos da Liga, esclarecem esta afirmação:

Na Liga, a ação principal de assistência é realizada pelo médico.

Todo o pessoal deve dar suporle para agilizar as ações do médico.

Sendo a ação do médico considerada como a ação assistencial principal do trabalho na Liga, o saber que o delimita e o orienta, é aquele que hegemonicamente tem sido reiterado, tanto no ensino como na prática de saúde deste século, ou seja, o saber médico assentado no modelo clínico biológico. Limitase, pois, o recorte do objeto do trabalho médico à presença de "hipertensão arterial" enquanto a "doença" e não uma das manifestações do sujeito considerado no todo social. Assim, delimitado o objeto como sendo a "pressão arterial acima do número considerado normal", as ações interventivas foram dirigidas à redução numérica desta "anormalidade", através da prescrição de medicamentos. Vejamos como a temática dos depoimentos dos agentes médicos da Liga ilustra estas afirmações:

A doença, e não o doente, é o objeto da ação do médico.

A ação assistencial médica da Liga tem por objetivo controlar a pressão arterial dos doentes através da prescrição de medicamentos.

Podem ainda serem justificadas as ações dos agentes não médicos mas, com a finalidade específica de melhorar a observância do doente à terapêutica medicamentosa, ou seja. o desenvolvimento de ações no sentido de garantir a eficácia da ação médica. Os temas, expressos em frases, descritos a seguir ilustram a representação dos agentes médicos sobre esta situação.

Quando surgem problemas tais como a ansiedade, o nervosismo, a obesidade ou mesmo "as questões existenciais" do doente, que não podem ser resolvidos pela terapêtuca medicamentosa, é feito encaminhamento a outros profissionais (psicólogo, nutricionista e assistente social).

As ações assistenciais do enfermeiro ("orientação, personalização, preocupação com o doente") têm a finalidade de aumentar a adesão do doente ao tratamento médico para que este seja mais eficaz.

O depoimento, aponta ainda mais para a desqualificação das ações e do saber dos agentes não médicos. neste caso referindo-se especificamente à enfermagem:

- À enfermagem cabe aquilo que do ponto de vista médico, é perda de tempo (orientar). 
LUZ (1979), em seu estudo sobre as instituições médicas no Brasil e estratégia de hegemonia, chama a atenção que "a institucionalização é projeto da totalidade da instituição(...) não se reduz à prática médica exercida no espaço institucional (...)". Envolve um conjunto de práticas e de agentes institucionais que as desenvolvem no sentido de engendrar efeitos instituintes sobre os pacientes. De outra forma, lembra a mesma autora que, para a ação médica garantir por si só os efeitos instituintes "(...) deveria ser de tal ordem que "passasse" aos pacientes os elementos fundamentais de uma estrutura de dominação: ordem, disciplina e hierarquia. Obedecer à autoridade do médico, seguir suas prescrições e recomendações e respeitar as normas do hospital. Estes seriam os objetivos garantidores da realização de um processo de hegemonia com efeitos instituintes políticos e econômicos: por um lado criar-se-ia um consumidor de médicos e remédios, isto $e$, de medicina, por outro ficaria garantida a organização disciplinada de uma população respeitadora de um certo tipo de saber e de autoridade".

O olhar biologizante do processo saúde-doença culmina por desqualificar o doente enquanto sujeito sócio-histórico, sendo a condição financeira para adquirir a medicação a única "questão social" considerada, como ilustram os temas, expressos em frases, extraídos dos depoimentos:

\section{O doente não prioriza a sua saúde e as suas condições de vida prejudicam o tratamento.}

Existe irresponsabilidade do doente em relação à sua doença.

Até este momento buscou-se caracterizar, através das temáticas dos depoimentos dos agentes, a organização do trabalho da Liga enquanto processo assistencial de saúde, o que representa, na prática, uma parcela secundária deste trabalho, utilizado apenas como meio ou suporte para a finalidade primordial deste serviço que é atualmente uma dada modalidade de investigação científica. Essa finalidade desencadeia um processo de trabalho ainda mais restrito do que o anteriormente descrito, já que, dissocia a investigação do ensino e da assistência.

Os objetivos iniciais da Liga, voltados mais ao ensino, foram se transformando integrando a assistência e pesquisa em certos casos, sendo que atualmente estão dirigidos mais à pesquisa.

Da parte dos médicos da Liga não há intenção assistencial nem didática.

Se por um lado a instituição hospitalar é estratégica em relação a um projeto de dominação-hegemonia controlada e regulada pelo Estado, por outro, não se reduz a isso. mantendo uma autonomia relativa face ao Estado, que lhe confere uma historicidade típica relativa à conjuntura institucional (LUZ; 1979). 
Desta forma é necessário buscar as articulaçōes entre as mudanças, ocorridas nos objetivos da Liga e a conjuntura institucional, nestes doze anos de existência, sem perder de vista a sua face de aparelho do Estado.

A Liga iniciou suas atividades num período (1980) em que já se passavam mais de dez anos do denominado novo hospital universitário, este "(...) destinado a uma grande massa estudantil, a uma clientela (previdenciária) crescente, que será um hospital sofisticado tecnologicamente e altamente especializado e se converterá não só no centro da prática do ensino médico, mas no centro da política médica do país a partir de 70" (LUZ; 1979).

Esta autora salienta ainda, que as transformações da prática médica e do "mercado da saúde" estão articuladas à implantação da auto-denominada reforma universitária no final dos anos sessenta e a um conjunto de fatores, alguns deles, sensíveis somente na segunda metade da década de setenta. Dentre estes, estão aqueles macro-institucionais relativos à política de saúde previdenciária e à política de educação especializante e tecnicista, além de outros fatores, também macro-sociais, como "(..) a influência da grande indústria químico-farmacêutica na produção-reprodução (ensino-pesquisa) do saber médico e a influência da indústria de equipamentos médico-hospitalares e laboratoriais no saber e na prática médica em todo o mundo ocidental a partir da segunda guerra e, no Brasil, desde o período desenvolvimentista de Juscelino Kubitschek" (LUZ; 1979).

"Estas influências far-se-ão no ensino sob a forma de especialização crescente, em geral não expressa nos currículos formais, setorializando-se o corpo humano em orgãos e aparelhos, privilegiando-se na formação médica as "especialidades" em detrimento de uma visão unitária do organismo" (LUZ;1979).

É assim que a Liga se instalou em 1980, como um serviço ambulatorial especializado em hipertensão arterial dentro de uma já especialidade da clínica médica, a Disciplina de Nefrologia da Faculdade de Medicina da Universidade de São Paulo.

À medida que os objetivos de assistência e ensino na Liga foram sendo secundarizados, em função da prioridade dada à investigação, houve uma redução gradual da participação dos estudantes nestas atividades consideradas extracurriculares. Em outras palavras, gradativamente foi ocorrendo uma incompatibilidade entre a demanda de ensino, para com os estudantes participantes da Liga, e a nova prioridade nos objetivos deste serviço. Assim sendo, em 1985, foi extinta a participação de estudantes de graduação na Liga.

Esse redirecionamento dos objetivos da Liga parece se contrapor as propostas de restruturação pretendidas, tanto no nível nacional pelo movimento de reforma sanitária, quanto no nível interno mais geral da instituição - Hospital das Clínicas da Faculdade de Medicina da USP (HC).

O período de março de 1983 a março de 1987, caracterizou-se pela primeira e única assunção de um superintendente eleito pela chamada comunidade hagaceana - funcionários vinculados ao $\mathrm{HC}$, estudantes e professores da 
Faculdade de Medicina. Iniciou-se também, neste período, uma luta pela autonomia e descentralização do HC.

No nível nacional, "no início dos anos oitenta, a crise econômica es timulou o Ministério da Previdência a adotar medidas de controle dos gastos. Na área da assistência médica, criaram-se, a partir de 1983, as Ações Integradas de Saúde.

Assim, pode-se relacionar o crescimento do atendimento assistencial na Liga, até a metade da década de 80, à criação das Ações Integradas de Saúde (AIS) que ampliaram o atendimento através do convênio com o INAMPS.

Em contrapartida na Liga, a partir de 1987, a redução das atividades assistenciais e a priorização das de pesquisa podem estar articuladas às consequências advindas da vinculação direta do HC à Secretaria de Estado da Saúde e da implementação do convênio firmado com o Sistema Unificado e Descentralizado de Saúde (SUDS).

$\mathrm{OHC}$, com a possibilidade de gerar recursos próprios por constituir-se em uma autarquia ,realizou, em 1988, um aditamento ao convênio com o SUDS. passando a integrar. em sua estrutura, uma Fundação de direito privado. a Fundação Faculdade de Medicina. Acentuou-se, nesta época, a transição dos objetivos da Liga mais voltados à assistência, à formação de recursos humanos e à investigação, para uma dada pesquisa, assistência e ensino, nesta ordem de prioridade.

Os temas expressos em frases, extraídos dos depoimentos, ilustram essa discussão.

\section{A finalidade da Liga é o estudo da hipertensão, o doente se constituindo em objeto de pesquisa.}

A ação do médico na Liga é a de desenvolver os protocolos de pesquisa propostos pela indistria farmacêulica, para gerar dinheiro.

A possiblidade de gerar recursos financeiros, através das atividades de investigação articuladas ao desenvolvimento de projetos das indústrias de medicamentos. limita o tipo de saber desenvolvido. como salientou o Ministro da Saúde, Professor Adib Jatene em entrevista ao Jornal o Estado de São Paulo (INDUSTRIA;1993) sobre a pesquisa encomendada pelos laboratorios multinacionais de medicamentos: "é o interesse industrial que predomina sobre o científico, ou mesmo sobre a população".

Desta forma. a priorização do trabalho na Liga dada ao desenvolvimento de pesquisa das indústrias de medicamentos privatiza os recursos públicos humanos e materiais a esse objetivo. em detrimento das ações assistenciais e de ensino.

E qual seria a razão da produção e reprodução deste saber?

Como já se salientou anteriormente, este saber biologizante sustenta o 
modelo clínico de assistência à saúde que responde de forma mais adequada às necessidades próprias do sistema capitalista por ser individual e medicalizante. A reiteração deste saber é,portanto, necessária à manutenção do sistema, principalmente, quando se organizam movimentos contra-hegemônicos.

$\mathrm{O} H \mathrm{HC}$, enquan to o maior complexo hospitalar público universitário do país e da América Latina, é uma instituição estratégica para a manu tenção do modelo de saúde hegemônico vigente, garantida através da práxis de seus agentes. Da mesma forma, o saber gerado nesta Instituição constitui um modelo a ser reproduzido nacionalmente. A Liga, enquanto serviço integrante do $\mathrm{HC}$, é um exemplo de resistência às propostas contra-hegemônicas geradas na década de 80 , pois ela reitera o saber perfeitamente integrado à indústria farmacêutica, consagrando a intervenção assistencial limitada ao tratamento medicamentoso. Além disso, a face de pesquisa identificada como primordial no processo de trabalho na Liga, coisifica o sujeito da intervenção reduzindo-o a uma quantificação da medida da pressão arterial que responde ou não a um determinado tipo de medicamento em investigação/experimentação.

A pretensa autonomia deste saber e, portanto, do poder médico alimentase do fetiche da titulação acadêmica, alienada da subordinação do trabalho médico ao projeto político-econômico do país.

A visão dos agentes, sobre o seu trabalho na Liga, limita-se a uma parte muito restrita do micro-espaço institucional onde exercem uma prática alienada de suas determinaçōes mais amplas.

Importante a salientar é que se não está clara. para os profissionais, a finalidade de manutenção da dominação de determinada classe através da reprodução de um dado saber e uma dada prática, não se colocam perspectivas para o desenvolvimento de um saber crítico, articulado a uma prática transformadora. Desta alienação da razão da produção científica decorre um cientificismo que coisifica tanto a obtenção da titulação acadêmica como as práticas institucionais, no caso da Liga, uma dada modalidade de investigação que, além de restringir a intervenção assistencial. consagra o saber dominante.

O Objeto deste processo de trabalho, identificado pelos agentes médicos como sendo o doente é também coisificado como a pressão arterial de um corpo humano, respondente ou não aos medicamentos experimentados.

Quem é este sujeito utilizado como objeto de pesquisa médica? Qual o grau de consciência que ele tem deste processo? Como ele reage ao enfoque medicalizante?

Essas questões certamente merecem ser investigadas profundamente, envolvendo reflexões sobre cidadania. sociedade de classes. processo saúdedoença, entre outros.

Em síntese pode-se dizer que as concepções dos agentes sobre o processo de trabalho da Liga expressam uma práxis reiterativa que estabelece uma naturalidade da relação objeto. finalidade e meios. consagrando e consolidando 
um dado saber específico, meio da ação interventiva no objeto. Esse processo de trabalho recortado fenomenicamente, somente na sua organização interna, traz poucas contradições.

CAR,M.R.;EGRY,E.Y. Dialetic to the labour process in the Hypertension League. Rev.Esc.Enf.USP,v.30, n.2, p. 297-309, aug. 1996.

This study deals with the health assistance phenomena as it occurs in a hypertension league. The purpose of this research is to aprehend the contradictions, both internal and external, to the League labour process phenomena and, doing so, to enable the quest of alternative solutions to the quality assistance of transformation. The investigation reveals that the health workers conceptions about their labour process express a reiterative, non-creative and non-reflexive praxis.This way, it configures itself as a dominant and ideological one, beyond the fact of being an instrumental knowledge of intervention over the Object.

UNITERMS: Labour Process. Hypertension.

\section{REFERÊNCIAS BIBLIOGRÁFICAS}

BRASIL. Ministério da Saúde. Secretaria Nacional de Programas Especiais de Saúde. Divisão Nacional de Doenças Crônico-degenerativas. Guia para controle da hipertensão arterial. Brasília. Centro de Documentação do Ministério da Saúde, 1983. (Série A:Normas e Manuais Técnicos, 10).

BRASIL. Ministério da Saúde. Secretaria Nacional de Programas Especiais de Saúde. Divisão Nacional de Doenças Crônico-degenerativas. Programa Nacional de Educação e Controle da Hipertensão Arterial. Normas Técnicas para o programa nacional de educação e controle da hipertensão arterial. Brasília, Centro de Documentação do Ministério da Saúde. 1988 (a). Série A: Normas e Manuais Técnicos. 47).

BRASIL: Ministério da Saúde. Secretaria Nacional de Programas Especiais de Saúde. Divisão Nacional de Doenças Crônico-degenerativas. Instituto Nacional de Assistência Médica da Previdência Social. Coordenadora de Ciência e Tecnologia. Doenças crônico-degenerativas: evolução e tendências atuais - I. Brasília. Centro de Documentação do Ministério da Saúde. 1988 (b). (Série 5: Cadernos. 2).

BREILH, J.; GRANDA, E. Investigaçăo da saúde na sociedade: guia pedagógico sobre um novo enfoque do método epidemiológico. São Paulo. Instituto de Saúde/ ABRASCO, 1986.

CAR.M.R. Da aparência à essência:a práxis assistencial dos trabalhadores da Liga de Hipertensão Arterial. Sao Paulo.1993. 125p. Tese (Doutorado) - Escola de Enfermagem. Universidade de São Paulo.

CHIAVERINI, R. et al. Hipertensão arterial para o clínico: etiopatogenia, diagnóstico, tratamento. Rio de Janeiro/São Paulo, Atheneu, 1985. 
CONSENSO Brasileiro para o tratamento da hipertensão arterial. Arq.Bras.Cardiol., v.56, p.A1-16, 1991. Suplemento A.

FIORIN, J.L.; SAVIOLI, F.P. Para entender o texto: leitura e redação. São Paulo, Ática, 1991.

GONÇALVES, R.B.M. O processo de trabalho em saúde. São Paulo. Departamento de Medicina Preventiva da Faculdade de Medicina da USP. 1988. Mimeografado/

GONÇALVES, R.B.M. Práticas de saúde: processos de trabalho e necessidades. SÆÉo Paulo, Departamento de Medicina Preventiva da Faculdade de Medicina da USP, 1992./ Mimeografado/

HUTCHINS, L.N. Tratamento medicamentoso da hipertensão arterial. Clín.Enf.Amer.Norte, v. 16, n.2, p.351-62, 1981 .

INDUSTRIA se apossou da pesquisa. O Estado de São Paulo. São Paulo, 7 març. 1993. p. 8

INFANTE, N.B. de; ALvarEZ, L. Sociedad y salud. Cali, Forma Precisas, 1991.

KOSIK, K. Dialética do concreto. Rio de Janeiro, Paz e Terra, 1986.

LAURELL, A.C. A saúde - doença como processo social. In: NUNES, E.D. (org.). Medicina social: aspectos históricos e teóricos. São Paulo, Global, 1983. cap. 4, p. 133-58.

LAURENTI, R. Epidemiologia da hipertensăo arterial. In: CHIAVERINI, R. et al. Hipertensao arterial para o clínico: etiopatogemia, diagnóstico, tratamento. São Paulo, Atheneu, 1985. cap.3, p.65-87.

LUNDE, P.K.M. SeleçÆ̌o e uso de medicamentos a nível internacional, nacional e local. In: LAPORTE, J.R.; TOGNONI, G.; ROZENFELD, S. Epidemiologia do medicamento: princípios gerais. Såo Paulo, HUCITEC/Rio de Janeiro. ABRASCO, 1989. cap.4, p.75-93.

LUZ, M.T. As instituiçōes médicas no Brasil: instituição e estratégia de hegemonia. Rio de Janeiro, Graal, 1979.

ORGANIZACION MUNDIAL DE LA SALUD. Hipertensión y cardiopatia coronariana: classificación y critério para los estudos epidemiológicos. Ginebra, 1958. (Séries de Informes Técnicos, 168).

SEMPLE, P.F.; LINDOP, G.B.M. An atlas of hypertension. New Jersey, The Parthenon Publishing Group, 1992. 